\title{
Calcium hydroxide nanosols for the consolidation of porous building materials - results from EU-STONECORE
}

\author{
Arnulf Daehne ${ }^{1}$ and Christoph Herm ${ }^{2 *}$
}

\begin{abstract}
Introduction: The main idea of the European STONECORE R\&D project (2008 to 2011) was to develop and evaluate nano materials for the use in refurbishment and conservation of historic monuments. A set of different calcium hydroxide ("lime") nanoparticles dispersed in alcohols (CaLoSiL ${ }^{\circledR}$ ) available on the market were tested. The general advantages attributed to alcoholic lime dispersions were: compatibility of the consolidant with the original building material, no limitation of penetration due to the particle size, and no mobilisation of soluble salts.
\end{abstract}

Results: The paper mainly reports the evaluation of lime nanosols for consolidation of lime mortar, gypsum stucco, and mural painting layers. In order to achieve a penetration behaviour which is adequate to the pore structure of the substrate, the composition of the nanosol as well as its application procedure had to be adjusted. This could be achieved by dilution, additives, or after-treatment of the surface. Apart from structural strengthening of porous structures the lime nanosols were tested for treatment of larger defects such as fissures, cracks, detachment, and delamination. For this purpose the nanosols were modified with additives, fillers, and aggregate. The developed lime nanosol formulations were applied to test sites at three historic monuments with promising results.

Conclusion: A 'modular system' was developed to meet all these conservation needs. These materials showed sufficient adhesive strength. They proved applicable for the consolidation of severely cracked limestone as well.

Keywords: Consolidation, Nanosol, Calcium hydroxide, Nanolime, CaLoSiL, Alcohol, Mortar, Stucco, Lime stone, Mural painting

\section{Introduction}

Conservation of historical buildings, sculptures or wall paintings requires materials which are compatible with the components originally used for construction. This means that the characteristics and behavior of the original system has to be respected and should not be substantially changed, especially in terms of porosity, stability and retreatability. However, the materials and components currently available do not fulfill these demands in all cases. Many examples are known in which the use of unsuitable materials, e.g. polymers, has caused additional damage.

\footnotetext{
* Correspondence: herm@hfbk-dresden.de

${ }^{2}$ Hochschule fuer Bildende Kuenste Dresden, POB 160 153, D-01288 Dresden, Germany

Full list of author information is available at the end of the article
}

In the context of the European collaborative project STONECORE [1] twelve partners, both enterprises and public research organizations, from seven countries joined in order to find a new approach for the refurbishment of stones, mortars and plasters used in the construction of historic monuments. The idea was to develop and test nano-materials compatible to those used during construction. The development and testing of calcium hydroxide nanosols was accompanied by comprehensive research in the field of non-damaging assessment methods.

The objectives of using calcium hydroxide nanosols were:

- treatment of natural stone and mortar with components that result in the formation of stone- 
like compounds with the same chemical and mineralogical composition (i.e. calcium carbonate),

- possibility to penetrate deep into damaged zones without limitations due to the particle size;

- high reactivity and fast reactions (such as carbonation) in the treated zones;

- high purity and defined composition;

- environmentally friendly system free from toxic admixtures.

From the literature, one concept already is known using calcium hydroxide nanoparticles which are dispersed in alcohols for conservation of wall paintings [2]. The particle size generally lays in the range of $130-300 \mathrm{~nm}$. This material is available on the market since several years [3]. It contains $5 \mathrm{~g} / \mathrm{L}$ calcium hydroxide in 2-propanol. However, this nanosol is produced from aqueous solution and needs elaborate purification during production. Within STONECORE project stable calcium hydroxide nanosols were synthesised directly from alcoholic solution. The nano-particles are sized in the range 50-250 nanometres. They are dispersed in different alcohols (ethanol, n-propanol, 2-propanol). The small size and electrostatic repulsion forces guarantee the stability of the sols. These are able to penetrate deep into deteriorated stones, mortars or plaster. These nanosols are available on the market with a concentration in a range of $5-25 \mathrm{~g} / \mathrm{L}$ [4]. There is also a higher concentrated "paste-like" product with a concentration of $300 \mathrm{~g} / \mathrm{L}$ in ethanol. A special product $\left(\mathrm{CaLoSiL}{ }^{\circledR}\right.$-Micro) contains calcium hydroxide particles with a particle sizes of 1-3 micrometres which may act as a crack-bypassing material in the porous building material. After evaporation of the alcohol, the calcium hydroxide particles are present in the treated material without any other residues. Conversion into calcium carbonate takes place in a similar way as for conventional lime by reaction with atmospheric carbon dioxide. Additionally, this reaction requires the presence of humidity. In some cases of application the formation of a white haze on the treated surface is observed. Reasons for this unfavourable behaviour may be low porosity or a high moisture content of the substrate as well as over-saturation of the material or quick evaporation of the solvent.

In the frame of STONECORE a wide range of materials were successfully treated for consolidation with the different CaLoSiL nanosols [5-7]. This paper concentrates on two conservation tasks: consolidation of mortar and filling of cracks and gaps [8]. Solvent-based calcium hydroxide dispersions open up the possibility of almost water-free and material-appropriate conservation of mortar. The other focus was the evaluation of calcium hydroxide nanosols for preparing water-free grouts. To achieve this, the modification of the solvent composition, the addition of thickeners, fillers, aggregates and calcium hydroxidedispersion with larger particle diameter were tested.

\section{Consolidation of mortar \\ Materials and methods \\ Model material}

- weak dolomitic lime mortar prisms, binder DL 85-S (EN 459-1) "Pelmer Kalk" from Rheinkalk Akdolit and quartz sand $(0.04 \ldots 1 \mathrm{~mm})$, binder : aggregate $=$ 1:32 mass/mass.

- weak gypsum mortar prisms from crushed gypsum mortar and quartz sand $(0.04 \ldots 1 \mathrm{~mm})$, final binder : aggregate $=1: 24$ mass $/$ mass.

Calcium hydroxide dispersions

Modified calcium hydroxide nanosols (see Figure 1, Figure 2, and Table 1).

2-1 and 2-2: E50, diluted with ethanol, increase of concentration during 6 applications (5/7.5/10/12.5 $15 / 25 \mathrm{~g} / \mathrm{L})$,

3-2: E50 diluted with acetone and ethanol (resulting ratio $60 \% / 40 \%)$

4-2: E50 diluted with acetone and ethanol (resulting ratio $60 \% / 40 \%$ ), increase of concentration during 6 applications (5/7.5/10/12.5 15/25 g/L).

5-1: E50 diluted with acetone and ethanol (resulting ratio $60 \% / 40 \%$ ), increase of concentration during 5 applications (5/12.5/12.5/25/25 g/L)

6-1: NP25, diluted in n-propanol (12,5 g/L) + HPC-gel,

7-1: E25 + CaLoSiL Micro $100+1 \mathrm{w} / \mathrm{w}$.

- application by immersion or pipette until saturation

- coating with hydroxypropylcellulose gel: Klucel ${ }^{\circledR} \mathrm{G}$, $0.5 \%$ mass in n-propanol. Curing of specimens: $>7$ days after application at $20^{\circ} \mathrm{C} / 65 \% \mathrm{RH}$.

Laboratory tests:

- staining with $\mathrm{pH}$-indicator (phenolphthaleine), $0.1 \mathrm{wt} \%$ in ethanol + water $(70+30)$

- three-point bending strength on mortar prisms $\left(2 \times 2 \times 10 \mathrm{~cm}^{3}\right)$ : testing velocity $\mathrm{v}=0.15 \mathrm{~mm} / \mathrm{min}$, distance between supports $=60 \mathrm{~mm}$, calculation of bending strength according to standard DIN EN $12372: 1999$ (average of three specimens).

- water accessible porosity under atmospheric pressure according to standard DIN EN 14617-1:2012

- thin-section microscopy.

\section{Results}

The effect of the strengthener firstly was tested on very weak dolomitic lime mortar specimens imitating material needing to be treated. The investigation of the mortar 


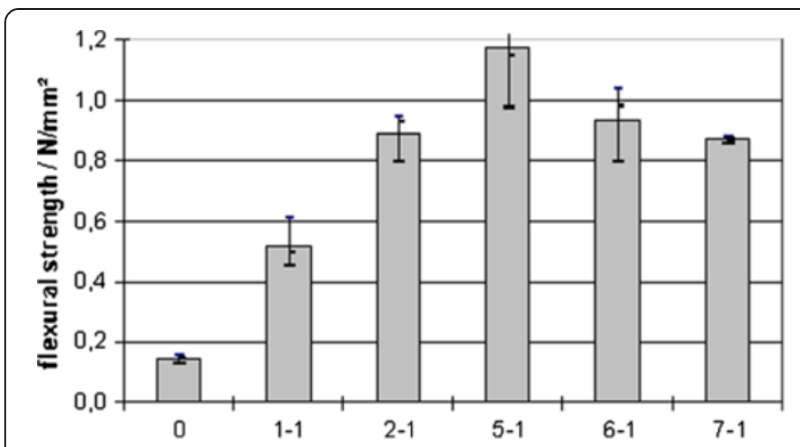

Figure 1 Three-point bending strength of weak dolomitic lime mortar (laboratory specimens, average of 3 specimens) before and after treatment with CaLoSiL nanosols: $0=$ untreated, 1-1: Calosil E25 (3 applications), 2-1: E25, diluted with ethanol, increase of concentration during 6 applications (5/7.5/10/12.5 15/ $25 \mathrm{~g} / \mathrm{L}), 5-1$ : E50 diluted with acetone and ethanol (60\%/40\%), increase of concentration during 5 applications (5/12.5/12.5/25/ $25 \mathrm{~g} / \mathrm{L}), 6-1:$ NP25, diluted in n-propanol (12,5 g/L) + HPC-gel, 6 applications, 7-1: E25 + Micro $100+1$ w/w, 3 applications.

specimens treated with calcium hydroxide nanosol has shown the accumulation of calcium hydroxide at the surface after evaporation (Figure 3). By comparison to the state immediately after impregnation (Figure 3) it can be followed that the accumulation is caused by backmigration of the nanoparticles during the evaporation of the solvent. The microscopic investigation showed the presence of consolidant in the sample pores, but also enrichment on the surface (Figure 4). In order to improve the distribution of the nanosol into the mortar and to avoid white haze on the surface, the application method was modified in four directions:

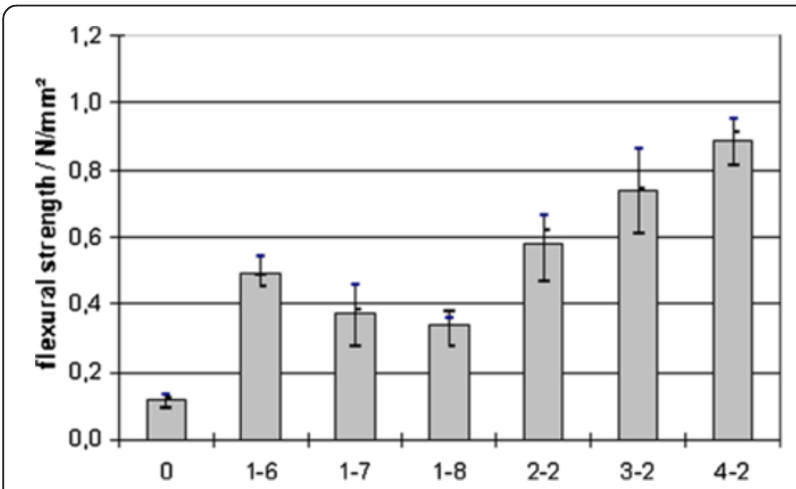

Figure 2 Three-point bending strength of weak gypsum lime mortar (laboratory specimens, average of 3 ) before and after treatment with CaLoSiL nanosols: $0=$ untreated, 1-6: E25 (3 applications), 1-7: IP25 (3 applications), 1-8: NP25 (3 applications), 2-2: E25, diluted with ethanol, increase of concentration during 6 applications (5/7.5/10/12.5 15/25 g/L), 3-2: E50 diluted with acetone and ethanol (60\%/40\%), 6 applications (12.5 g/L), 4-2: E50 diluted with acetone and ethanol $(60 \% / 40 \%)$, increase of concentration during 6 applications (5/7.5/10/12.5 15/25 g/L). i) use of diluted nanosols $(5 \ldots 25 \mathrm{~g} / \mathrm{L})$ and a stepwise increase of concentration during up to six applications,

ii) addition of acetone which already was reported in the literature with promising results (Schönhofer K (2006) Calciumhydroxid-Sol Ein Festigungsmittel für Historische Putze. Diploma Thesis, Fachhochschule Cologne, Germany, (unpublished) p 111),

iii) coating of the treated surfaces with alcoholic hydroxypropyl cellulose gel,

iv) combination of CaLoSiL nanosol with coarser calcium hydroxide suspensions (CaLoSiL -Micro), "bimodal dispersion".

In each case, the absorption of consolidant reached $2 . .3 \mathrm{wt} \%$ after drying, which equals an increase in binder content up to $76 \mathrm{wt} \%$ (as calculated based on the original mix ratio of the mortar samples). Dilution (i), combined with gel-coating (iii) reduced the evaporation effectively and led to an even distribution of the calcium hydroxide (Figure 5). The addition of micron-sized calcium hydroxide suspension (iv) proved effective in preventing backmigration as well (Figure 5).

The bending strength of the very weak dolomitic lime mortar was increased significantly by three treatments with CaloSiL E25 (from $0.14 \mathrm{~N} / \mathrm{mm}^{2}$ to $0,52 \mathrm{~N} / \mathrm{mm}^{2}$, see Figure 1). The use of IP25 and NP25 resulted in slighter increase mechanical strength $\left(0.34 \ldots 0.49 \mathrm{~N} / \mathrm{mm}^{2}\right)$. The modified application of the nanosols resulted in even higher mechanical strength of the mortar with almost similar increase of more than $500 \%$ compared to the untreated material: diluted nanosol (5..25 g/L) (Figure 1), and coating with hydroxypropyl cellulose gel after application of nanosol diluted with acetone (Figure 1). The combination of stepwise increased concentration and acetone admixture showed the best results $\left(1.18 \mathrm{~N} / \mathrm{mm}^{2}\right)-$ about double increase of the strength of the pure E25 treatments and about $700 \%$ compared to the untreated material (Figure 1). Finally, the combination of CaLoSiL nanosols with coarser calcium hydroxide suspensions (CaLoSiL -Micro) resulted in significantly increased mechanical strength $\left(0.44 \ldots 0.87 \mathrm{~N} / \mathrm{mm}^{2}\right)$ as well (Figure 1). After treatment with these various calcium hydroxide nanosol formulations and application methods the dolomitic lime mortar showed a slight reduction of water accessible porosity from $36 . .39 \mathrm{vol} \%$ (untreated) to 30. . .34 vol.\% (treated).

Subsequently, the effect of the calcium hydroxide nanosols was tested also on very weak gypsum mortar specimens imitating material needing to be treated. Generally, the same approach was made as for dolomitic lime mortar. In each case, absorption of consolidant has reached 2...3 wt\% (after drying) which equals an increase in binder content by up to $70 \mathrm{wt} \%$ (as calculated based on the original mix ratio of the mortar samples). 
Table 1 Commercial calcium hydroxide nanosols used for the consolidation of mortar

\begin{tabular}{llclc}
\hline & Product & Particle size/nm & Solvent & Concentration/g/L \\
\hline E25 & CaLoSiL E25 & $130-300$ & ethanol & 25 \\
E50 & CaLoSiL E50 & $130-300$ & ethanol & 50 \\
IP25 & CaLoSiL IP25 & $130-300$ & 2-propanol & 25 \\
NP25 & CaLoSiL NP25 & $130-300$ & n-propanol & 25 \\
& CaLoSiL -Mikro & $1000-3000$ & ethanol & 120 \\
\hline
\end{tabular}

Similar to the dolomitic lime mortar the bending strength of the gypsum mortar prisms could be increased by treatment with the strengtheners: Three treatments with CaloSiL E25 lead from $0.114 \mathrm{~N} / \mathrm{mm}^{2}$ to $0,50 \mathrm{~N} / \mathrm{mm}^{2}$ (Figure 2). The use of IP25 and NP25 resulted in slighter increase mechanical strength of 0.34 and $0.38 \mathrm{~N} / \mathrm{mm}^{2}$ ), resp. (Figure 2). The modified application of the nanosols resulted in even higher mechanical strength of the gypsum mortar up to $0.74 \mathrm{~N} / \mathrm{mm}^{2}$ (increasing concentration of diluted ethanolic nanosol during six applications and diluted nanosol with $40 \%$ acetone, six applications, see Figure 2). The combination of stepwise increased concentration and acetone admixture again show the best results of about $680 \%$ increase compared to the untreated material (Figure 2).

\section{Consolidation of cracks and gaps Approach}

The use of water-free lime-based grouts for the conservation of wall paintings, plaster and stucco is of great interest, for example if salt content or humidity-sensitive paint layers are present. A grout on the basis of CaloSiL nanosol already available on the market [9] still contains a fraction of water. The aim was to develop suitable grouting masses using different products of the CaLoSiL product line and admixtures discussed below. For the consolidation of thin layered delaminations and fixation of fine cracks and fissures, unmodified nano-dispersions are not suitable because of their low viscosity. Thus, gaps and fissures too small for the injection of filler containing grouts (width $\mathrm{b}<1 \mathrm{~mm}$ ) should be consolidated with a thickened nanosol. The necessary retention of the applied nanosol in small spaces should be enhanced by modification of the solvent composition or addition of gelling agents. A third approach was the preparation of a "bimodal" dispersion using nanosol with admixture of CaLoSiL-Micro, a calcium hydroxide dispersion with larger particle sizes. Another task was to find possibilities for the consolidation of delaminations and for fixation of cracks and fissures with a width $\mathrm{b}>1 \mathrm{~mm}$. Here, pure nanosols are not suitable because of their low viscosity and insufficient strength. Thickening of the nanosol with hydroxypropylcellulose did not lead to any improvement. Variation of the binder content caused shrinking-crack formation and decrease of strength. In preliminary tests, promising results were found using CaLoSiL-Mikro mixed with CaLoSiL E50 as binder. Furthermore, for increase of viscosity and prevention of shrinkage the use of filler is necessary.

\section{Materials and methods}

Binder: CaLoSiL E50, CaLoSiL-Micro (details see Table 1) Fillers:

- Chalk of Champagne (natural calcium carbonate, grain size max. $30 \mu \mathrm{m})$

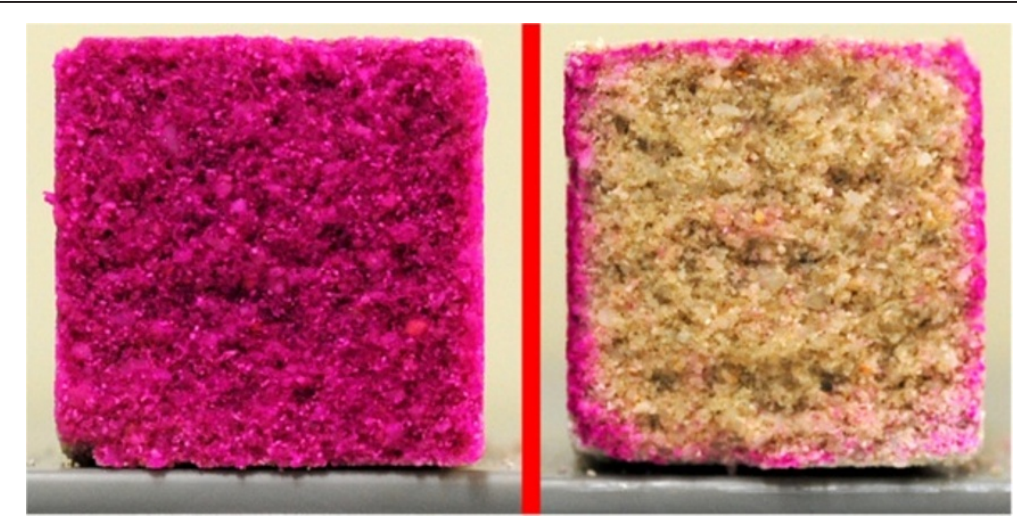

Figure 3 Distribution of calcium hydroxide nano-particles in mortar samples indicated by the red colour of the phenolphthalein indicator (size $=2 \mathrm{~cm} \times 2 \mathrm{~cm}$ ), left: immediately after saturation with CaLoSiL NP25, right: after 24 hours. 


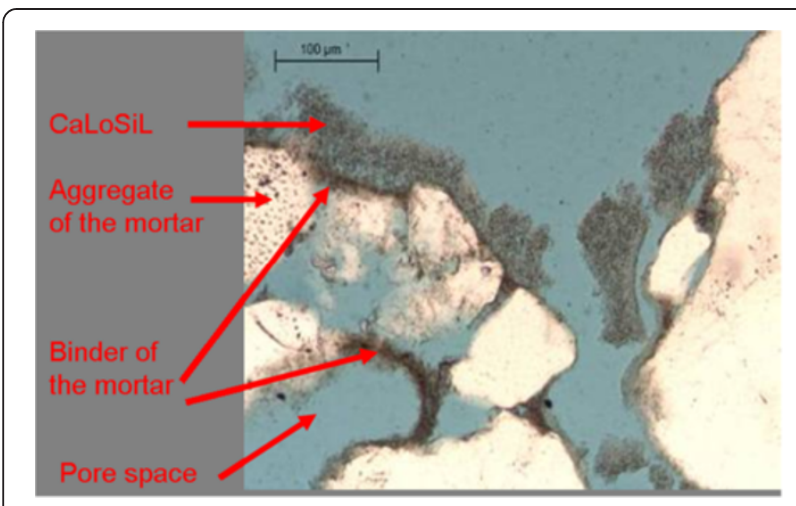

Figure 4 Microscopic image of a thin section (//Pol) of dolomitic lime mortar (laboratory specimen) after treatment with nanosol (CaLoSiL) and after complete curing, showing a cross section including the surface (top) (Photograph: Thomas Köberle).

- Marble powder (Marmormehl extra 58520, Kremer Pigmente $\mathrm{GmbH}$, grain size max. $32 \mu \mathrm{m})$

- Hollow glass microspheres (Scotchlite ${ }^{\text {tm }}$ S22 $(75 \mu \mathrm{m})$ and Scotchlite ${ }^{\mathrm{Tm}} \mathrm{K} 1(\max .120 \mu \mathrm{m})$ The used mixture was calculated in order to achieve dense packing: chalk or marble powder $+\mathrm{S} 22+\mathrm{K} 1=5,8+1,25+1$ by mass.

Thickener: hydroxypropylcellulose Klucel ${ }^{\circledR}$ G, 0.5\%mass in ethanol + water $(1+1 \mathrm{v} / \mathrm{v})$.

For comparative studies a commercial water-based limegrout was used (PLM-A, c.t.s, Altavilla Vicentina/Italy).

Laboratory tests:

i) Limestone samples: In order to simulate a heavily damaged substrate with the required damage patterns, limestone samples were used as a medium for laboratory tests. A fine micritic limestone from Fuping County (Shaanxi Province, PR China) was burned at $700^{\circ} \mathrm{C}$ and slaked afterwards using damp sand.
Multilayered delaminations as well as severe cracks were formed. The defects had a width up to about 1 millimetre. The consolidants were applied three times usind a syringe; curing of specimens: $20 \ldots 30$ hours after application at $20^{\circ} \mathrm{C} / 65 \% \mathrm{RH}$ (Figure 6). Evaluation of the consolidation based on optical appearance and stability against manual brushing.

ii) "Sandwich samples": In order to simulate filling of fine fissures and delaminations, the grout was applied between two brick cubes with a contact surface of c. $2 \times 2 \mathrm{~cm}^{2}$. Mixtures mentioned here were: CaLoSiL-Micro + CaLoSiL E50 + filler (mass/ mass/mass): $\mathrm{H} 24=4+2+1, \mathrm{H} 28=4+4+1, \mathrm{H} 31=$ $8+8+1, \mathrm{H} 32=4+4+1$ (see Figure 7). The filler for $\mathrm{H} 24, \mathrm{H} 28$, and H31 contained chalk; H32 contained marble powder. Curing of specimens: 7 days after application at $20^{\circ} \mathrm{C} / 65 \% \mathrm{RH}$. The adhesive strength was tested using a universal mechanical testing machine (three specimens per mixture). Testing velocity $\mathrm{v}=0.15 \mathrm{~mm} / \mathrm{min}$.

iii) Reconnected mortar prisms: Before treatment, dolomitic lime mortar prisms as described above had undergone a three-point bending strength measurement as described above. Subsequently, grouting mixtures were applied to reconnect them. Mixtures mentioned here were: CaLoSiL E50 + CaLoSiL-Mikro + thickener (mass/mass/volume): no.15 $=1+1+0.4$, no.18 $=1+2$ +0.6 , no. $19=1+3+0.8$, no. $20=1+1+0.2$ (see Figure 8). After six applications of consolidant with syringes into the gap and curing ( 7 days after application at $20^{\circ} \mathrm{C} / 65 \% \mathrm{RH}$ ), bending strength of the reconnected prisms was measured once more as described above (single specimens).

\section{Results}

i. Limestone-samples

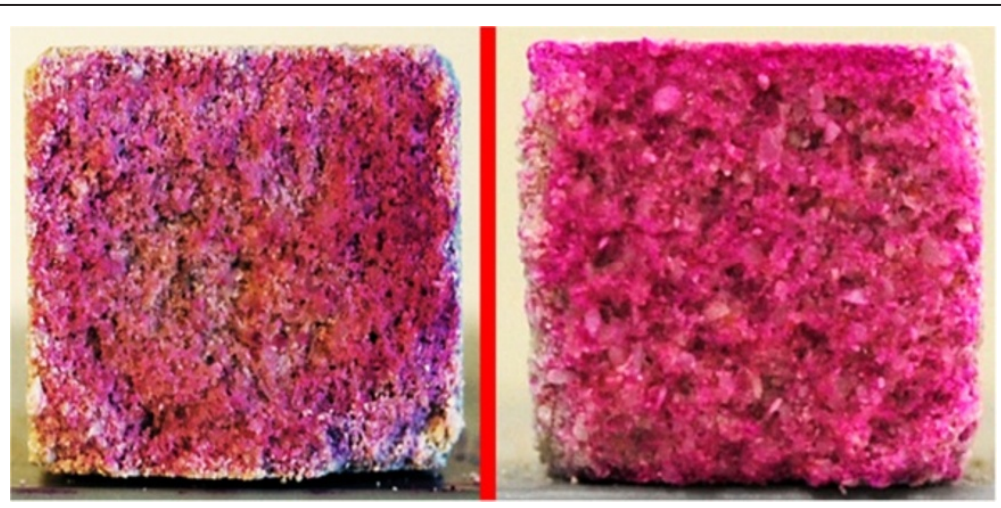

Figure 5 Distribution of calcium hydroxide nano-particles in mortar samples after 24 hours (phenolphthalein indicator) $($ size $=2 \mathrm{~cm} \times$ $2 \mathrm{~cm}$ ), left: modification of the solvent (CaLoSiL NP12,5 g/L, 40\% acetone) and after-treatment with HPC-gel in ethanol (6-1), right: bimodal dispersion containing CaLoSiL Micro and CaLoSiL E-25 (7-1). 

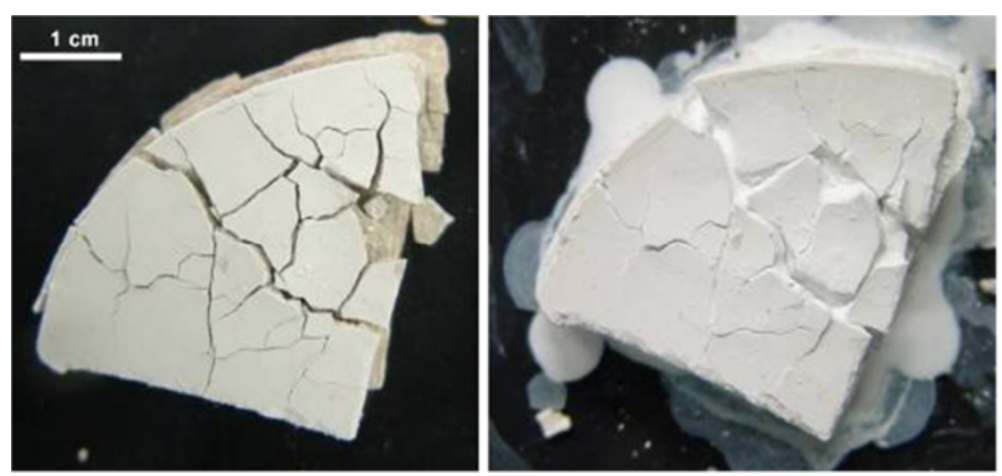

Figure 6 Artificially aged limestone sample before (left) and after (right) treatment with modified nanosol.

The best results were achieved with the admixture of hydroxypropylcellulose solution with water content. Although necessary, the water content can be reduced to a total of $2.5 \mathrm{vol} \%$. Despite the good consolidation effect, only very fine defects were filled by this agent after up to three applications. For the filling of larger gaps and fissures of $0.5-1.0 \mathrm{~mm}$ width a second test series was carried out using more highly concentrated CaLoSiL E50 and CaLoSiL-Micro dispersion. After a pre-treatment with the already positively tested modifications, the new modifications were applied to stone as a second consolidation measure. The $1+1$ mixture of CaLoSiL E50 and CaLoSil-Micro with addition of hydroxypropylcellulose-gel proved to be suitable for completing the consolidation of fine delaminations and fissures. A higher content of CaLoSiL Micro in the mixture showed in turn worse results, because of formation of shrinkage cracks.

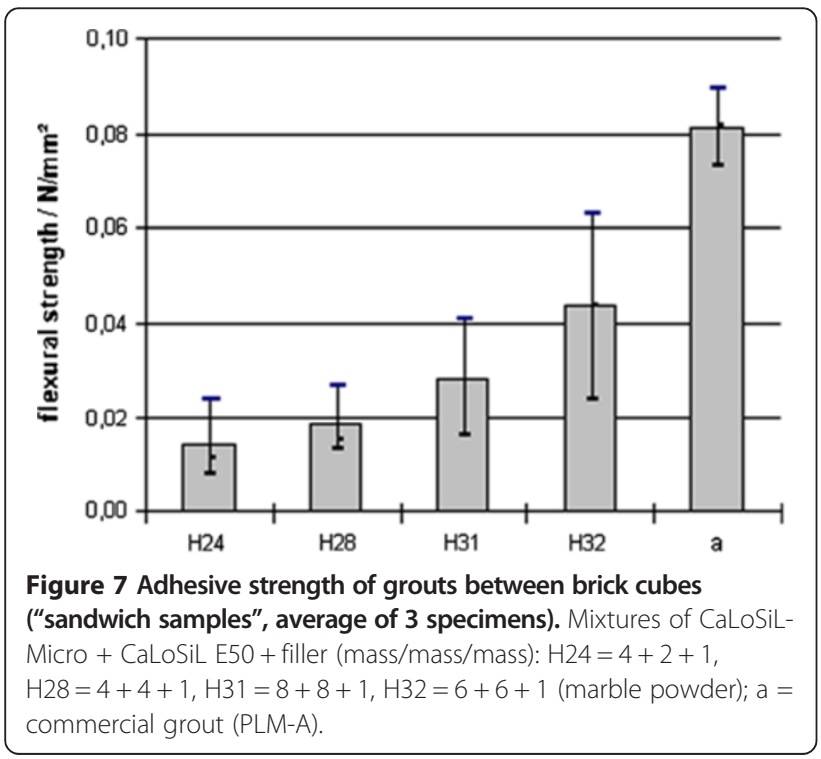

ii. "Sandwich samples"

A second laboratory test series was carried out with "sandwich samples", where grout was applied between two brick cubes. The adhesive strength was measured (Figure 7). Mixtures of equal masses of CaLoSiL-Micro and CaLoSiL E50 nanosols (ratio $1+1$ by mass) gave the best results. Here, the ratio of microparticles and nanoparticles is c. $70: 30 \mathrm{~m} / \mathrm{m}$. Using the filler mixture as given above, the best grout contained $6+6$ mass fractions of calcium hydroxide dispersions and 1 mass fraction of filler. Using marble powder instead of chalk in the filler showed the potential for improvement The maximum measured adhesion strength $\left(0.044 \mathrm{~N} / \mathrm{mm}^{2}\right.$, Figure 7) reached c. $54 \%$ of the strength of a commercial grout $\left(0.082 \mathrm{~N} / \mathrm{mm}^{2}\right)$ and thus was comparably high and suitable for many demands (Figure 7). The best performing mixtures mentioned here also developed sufficient adhesive power to the

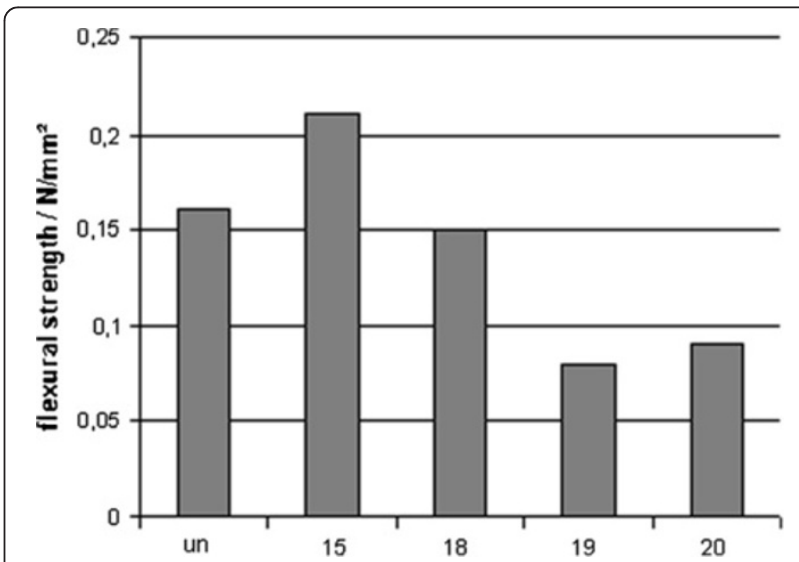

Figure 8 Three-point bending strength $\left(\mathrm{N} / \mathrm{mm}^{2}\right)$ of mortar prisms, reconnected with thickened nanosols (single measurements): mixtures of CaLoSiL E50 + CaLoSiL-Micro + thickener (mass/mass/ volume): $15=1+1+0.4,18=1+2+0.6,19=1+3+0.8,20=1+$ $1+0.2$, six applications each, un $=$ untreated. 

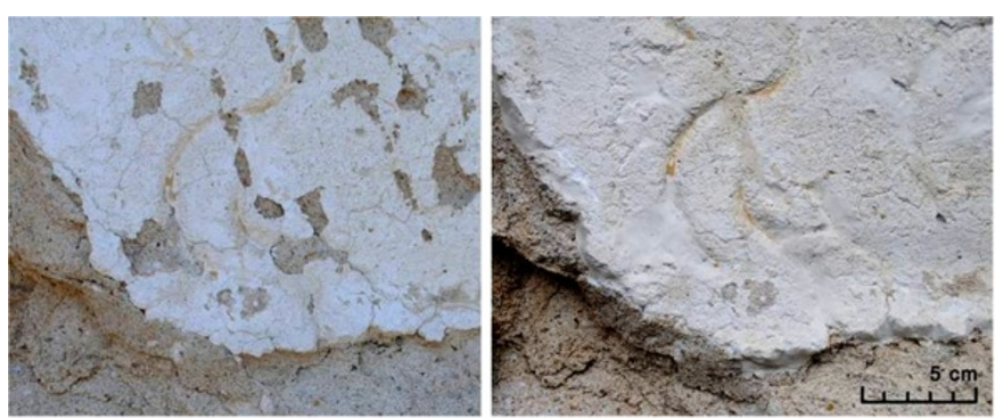

Figure 9 Leuben castle, eastern facade, tympanum, left part of test area 1: detail of the demonstration area for fine stucco consolidation before (left) and after (right) treatment.

substrate as indicated by cohesion failure in the grout, in contrary to adhesion failures in most other cases.

iii. Reconnected mortar prisms

In a third test series mixtures of CaLoSiL-Micro, CaLoSiL E50, and hydroxypropylcellulose solutions with different water content were applied to reconnect broken dolomitic lime mortar prisms. The strength after the treatment should be at least equal to the previous strength of the prism. As in the case (ii), the $1+1$ mixture of CaLoSiL E50 and CaLoSiLMikro with addition of hydroxypropylcellulose solution in ethanol and water developed sufficient strength $\left(0.21 \mathrm{~N} / \mathrm{mm}^{2}\right.$, Figure 8). A higher content of CaLoSiL-Micro or a lower content of hydroxypropylcellulose solution resulted in lower stability of the joint (Figure 8). Thus, the mixtures described here proved suitable for completing the consolidation of delaminations and cracks.

\section{Tests on historic monuments}

The modified application techniques and composition of CaLoSil nanosols have been tested and demonstrated successfully on two objects in Germany, Saxony State, and an ancient Roman excavation site in Italy.

\section{Leuben castle}

In Leuben Castle (17th century AD), deteriorated dolomitic lime plaster and lime stucco was consolidated with modified CaLoSiL/CaLoSiL-Mikro mixtures as summarised above. Even the addition of a very low amount of CaLoSiL-Micro (e.g. $1 \% \mathrm{v} / \mathrm{v}$ ) to any kind of CaLoSiL-nanosol improved the depth distribution of the consolidant and the mechanical strength of the treated mortar. Detachments and fissures behind the fine stucco layer were filled by injection of a mixture of CaLoSiL, CaLoSiL-Micro and HPC. Edges and losses were puttied using a paste of CaLoSiL-Micro, quartz sand, natural chalk and pigment (Figure 9).

Additionally, the mixtures thickened with cellulose ether proved useful for the consolidation of a wall painting on dolomitic lime plaster (strengthening of mortar, grouting of voids, completion of plaster losses, injection of fissures in the plaster, paint layer consolidation, and puttying of paint layer (Figure 10).

\section{Dahlen castle}

In Dahlen Castle (18th century AD) the above mentioned mixtures and modifications of calcium hydroxide nanosols proved also successful for the consolidation of gypsum mortar and white gypsum stucco (Figure 11).
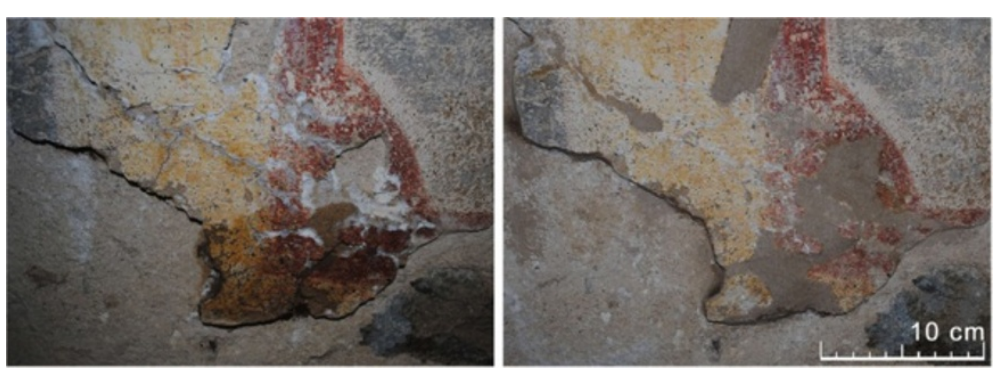

Figure 10 Leuben castle, room 012, part of test area 2: demonstration area for paint layer consolidation during (left) and after (right) the treatment. 


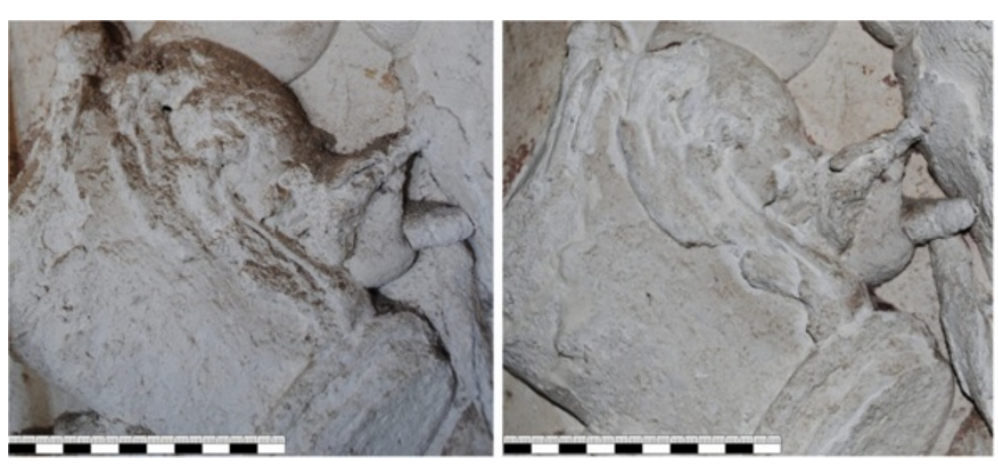

Figure 11 Dahlen castle, white salon, western wall, right part of test area 1: demonstration area for white gypsum stucco consolidation before (left) and after (right) treatment.

\section{Herculaneum excavation site}

Ancient Roman frescoes at „Herculaneum"excavation site at Ercolano (Napoli, Italy) suffer from delamination paint layers caused by salt efflorescence and locally as a consequence of former treatments. By request of the Herculaneum Conservation Project (HCP) the suitability of CaLoSiL nanosols for conservation of those paint layers was tested. Firstly, delamination of the surface layer which had previously been treated with acrylic resin could be flattened and consolidated by application of CaLoSiL E25. Secondly, the flaking surface of a blue fresco paint layers could be treated successfully by application of CaLoSiL E25, too (Figure 12).

\section{Conclusions}

Laboratory investigations into the action effects of calcium hydroxide nanosols focused on distribution and retention of the applied nanosols. It was found that for structural consolidation of dolomitic lime mortar and gypsum mortar either dilution of the nanosols and stepwise application or after-treatment with cellulose ether gels resulted in an strength increase of up to seven times of the untreated mortar. Even better results are possible by a combination of the single methods. The addition of a low amount of CaLoSiL-Micro to CaLoSil nanosols improved the depth distribution of the consolidant and the mechanical strength of the treated mortar, too. Additionally, back-migration and formation of white haze could be avoided by these application procedures.

In order to match specific conservation demands of deteriorated plaster, wall painting, and stuccowork, a "module system" for modifying the nanosols was developed. For grouting and filling a mixture of CaLoSil and CaLoSiL-Micro nanosols can either be thickened with cellulose ether or can be filled. Putties and repair mortars are based on pure CaLoSiL-Micro with filler or aggregate and pigment added. The test series on grouts performed so far demonstrate the feasibility of creating

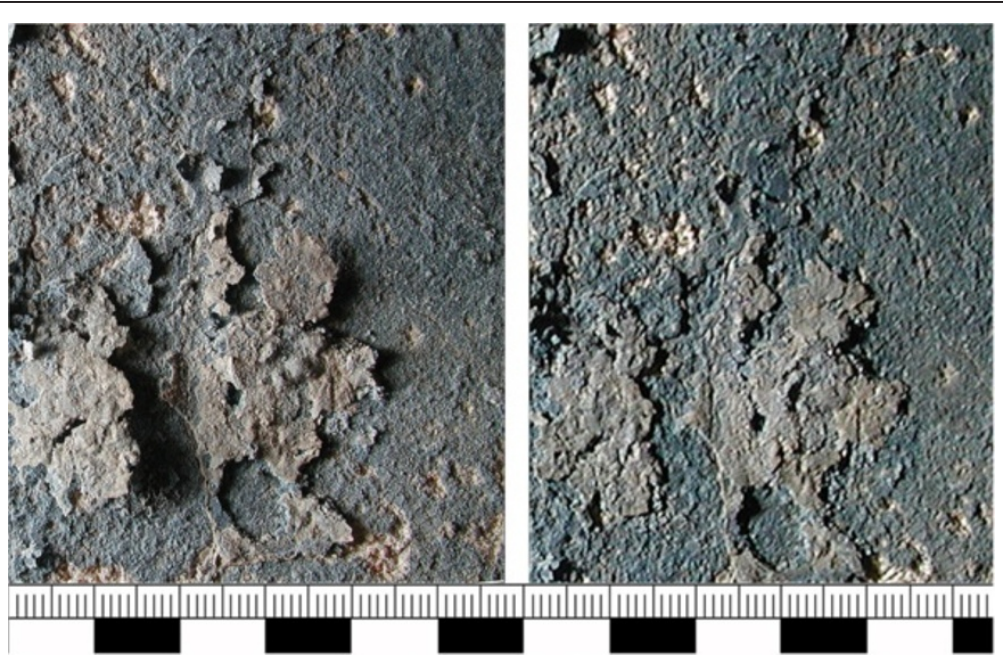

Figure 12 Herculaneum excavation site, "Casa dei Cervi", room 16: Trial area for paint layer consolidation before (left) and after treatment (right). 
almost water-free lime-bound grouts with suitable properties. The achievable mechanical strength of the grouts is acceptable in certain cases, although pure lime bonding reaches its natural limits. It cannot compete with hydraulically bound lime grouts for stronger consolidation treatments (e.g. large-scale reconnection of plaster). On the other hand the nano-lime based grouts open up new possibilities for the consolidation of fragile paint or plaster with water sensitivity.

Still necessary are additional studies in the aging properties of conservation material based on lime nano dispersions. Furthermore, efficiency in the presence of soluble salts has not yet been studied in detail.

\section{Competing interests}

The authors declare that they have no competing interests.

\section{Authors' contributions}

AD has designed experimental work, acquired and interpreted data, and performed tests on historic sites. $\mathrm{CH}$ has evaluated data and drafted the manuscript. Both authors read and approved the final manuscript.

\section{Acknowledgements}

The research leading to these results has received funding from the European Community's Seventh Framework [FP7/2007-2013] under grant agreement No 213651 (STONECORE).

The authors wish to thank the following persons and institutions for making possible the results presented in this paper: Dipl. Geol. Thomas Köberle and Dipl. Rest. Thomas Schmidt, all STONECORE project partners, namely Prof. Dr. Gerald Ziegenbalg, Herculaneum Conservation Project (HCP), namely Jane Thompson and Alessandra De Vita.

\section{Author details}

${ }^{1}$ Schloss 17, D-04600 Altenburg, Germany. ${ }^{2}$ Hochschule fuer Bildende Kuenste Dresden, POB 160 153, D-01288 Dresden, Germany.

Received: 5 February 2013 Accepted: 14 March 2013

Published: 09 April 2013

\section{References}

1. "Stone Conservation for Refurbishment of Buildings", granted by the European Commission in the Seventh Framework Programme (01.09.2008 to 31.8.2011). Grant agreement No. 213651. See: www.stonecore-europe.eu (31.07.2010)

2. Giorgi R, Dei L, Baglioni P (2000) A new method for consolidating wall paintings based on dispersions of lime in alcohol. Stud Conserv 45:154-161

3. Nanorestore ${ }^{\circledR}$, from: CTS Srl. , Altavilla Vicentina/Italy. See: www.ctseurope. com (31.07.2012)

4. CaLoSiL ${ }^{\circledR}$, from: IBZ Salzchemie. , Freiberg/Germany. See www.ibz-freiberg. de (31.07.2012)

5. Drdácký M, Sližková Z, Ziegenbalg G (2009) A nano approach to consolidation of degraded historic lime mortars. J Nano Res 8:13-22

6. Ziegenbalg G (2008) Colloidal calcium hydroxide - a new material for consolidation and conservation of carbonatic stones. In: Lukaszewicz $\mathrm{E}$, Niemcewicz P (ed) Proceedings of the 11th international congress on deterioration and conservation of stone, 15-20 September 2008. Torun, Uniwersitet Mikolaja Kopernika, Torun, Poland, pp 1109-1115

7. Maryniak-Piaszczynski E, Egloffstein P, Ziegenbalg G (2008) The portal in Tholey - unconventional method for the preservation of scaling and shelled sandstone. In: Lukaszewicz E, Niemcewicz P (ed) Proceedings of the 11 th international congress on deterioration and conservation of stone, 15-20 September 2008. Torun, Uniwersitet Mikolaja Kopernika, Torun, Poland, pp 1247-1256
8. Dähne A (2012) The results are presented in more detail in: Die Anwendung alkoholischer Calciumhydroxid-Nanodispersionen und Calciumsulfat-Dispersionen für die Konservierung von Putz, Stuck und Malschichten, Dissertation Hochschule für Bildende Künste Dresden. delivered 15.09.2012

9. CaloXil Injection Grout ${ }^{\circledR}$, from: IBZ Salzchemie., Freiberg/Germany. See www.ibz-freiberg.de (04.04.2013)

doi:10.1186/2050-7445-1-11

Cite this article as: Daehne and Herm: Calcium hydroxide nanosols for the consolidation of porous building materials - results from EU-STONECORE. Heritage Science 2013 1:11.

\section{Publish with ChemistryCentral and every scientist can read your work free of charge \\ "Open access provides opportunities to our colleagues in other parts of the globe, by allowing anyone to view the content free of charge." W. Jeffery Hurst, The Hershey Company. \\ - available free of charge to the entire scientific community \\ - peer reviewed and published immediately upon acceptance \\ - cited in PubMed and archived on PubMed Central \\ - yours - you keep the copyright \\ Submit your manuscript here: \\ http://www.chemistrycentral.com/manuscript/<smiles>c1ccccc1</smiles> \\ ChemistryCentral}

